\title{
The Vibration Analysis of Diesel Engine with Hydrogen-Diesel Dual Fuel
}

\author{
${ }^{1}$ Boonthum Wongchai, ${ }^{1}$ Porranat Visuwan and ${ }^{2}$ Sathaporn Chuepeng \\ ${ }^{1}$ Department of Mechanical Engineering, Faculty of Engineering, \\ Kasetsart University, 50 Ngam Wong Wan Rd, Ladyaow Chatuchak Bangkok 10900, Thailand \\ ${ }^{2}$ Department of Mechanical Engineering, Faculty of Engineering at Si Racha, \\ Kasetsart University, Si Racha Campus, 199 M.6, Tungsukhla, Si Racha, Chonburi, 20230, Thailand
}

Received 2012-09-22, Revised 2012-10-12; Accepted 2013-01-28

\begin{abstract}
The diesel engine vibration is one of the main problems of engine damage. When the hydrogen-diesel dual fuel is used, it may affect the engine vibration. Therefore, it is necessary to study the effect of hydrogendiesel dual fuel. The regression analysis is used to find the relations between hydrogen percentage and the engine vibration. The results for all cases found that the relation between the Average Peak Acceleration (APA) and hydrogen percentage $\left(\% \mathrm{H}_{2}\right)$ can predict by using linear equation with average coefficient of determination $\left(\mathrm{R}^{2}\right)=0.8973$ or 2 nd polynomial equation with $\mathrm{R}^{2}=0.9592$. All graphs are the decreasing function. APA can decrease by increasing $\% \mathrm{H}_{2}$. The relation between the average peak acceleration and hydrogen percentage can predict by using linear equation or 2 nd polynomial equation. The average peak acceleration can decrease by increasing hydrogen percentage. In the other word, the engine vibrations can decrease by increasing hydrogen percentage.
\end{abstract}

Keywords: Engine Vibration, Hydrogen-Diesel Dual Fuel, Diesel Engine, Hydrogen, Accelerometer

\section{INTRODUCTION}

The engine vibration is one of the main factors in engine design and engine maintenance (Cheng et al., 2012; Taghizadeh-Alisaraei et al., 2012). The engine vibration can measure by using the displacement sensor, the velocity sensor (Cheng et al., 2012), the Barelli et al., 2009; Carlucci et al., 2006), the engine acoustic pressure (Barelli et al., 2009). We can decrease it by using springs and dampers to support the engine.

In diesel engine, the alternative fuels are using to mix with diesel oil as the dual fuels for decreasing diesel oil consumption (Lata et al., 2011; Escalante and Fernandez, 2010; Selim, 2001; Banapurmatha et al., 2008; Huzayyin et al., 2004). The hydrogen-diesel dual fuel is one of the main choices because hydrogen can be produced from various sources such as water (Korakianitis et al., 2010; Miyamoto et al., 2011; Saravanana et al., 2007; Shin et al., 2011; Wu and Wu, accelerometer (Taghizadeh-Alisaraei et al., 2012;

2012). However, addition of hydrogen in diesel engine affect to the engine vibration (Barelli et al., 2009).

\section{MATERIALS AND METHODS}

\subsection{Test Engine}

In the present study, a single cylinder, direct injection, Kubota "RT100 plus" diesel engine is used. The engine details are summarized in Table 1 and Fig. 1 shows its setup with the engine test bed.

Table 1. Test engine specification

\begin{tabular}{ll}
\hline Maker & Kubota \\
\hline Model & RT100 DI \\
Number of cylinder & 1 \\
Bore $\times$ Stroke & $88 \mathrm{~mm} \times 90 \mathrm{~mm}$ \\
Displaced volume & $547 \mathrm{~cm}^{3}$ \\
Compression ratio & $18: 1$ \\
Maximum power & $7.4 \mathrm{~kW} @ 2,400 \mathrm{rpm}$ \\
Maximum torque & $3.4 \mathrm{~kg} \cdot \mathrm{m} @ 1,600 \mathrm{rpm}$ \\
\hline
\end{tabular}

Corresponding Author: Boonthum Wongchai, Department of Mechanical Engineering, Faculty of Engineering, Kasetsart University, 50 Ngam Wong Wan Rd, Ladyaow Chatuchak Bangkok 10900, Thailand 


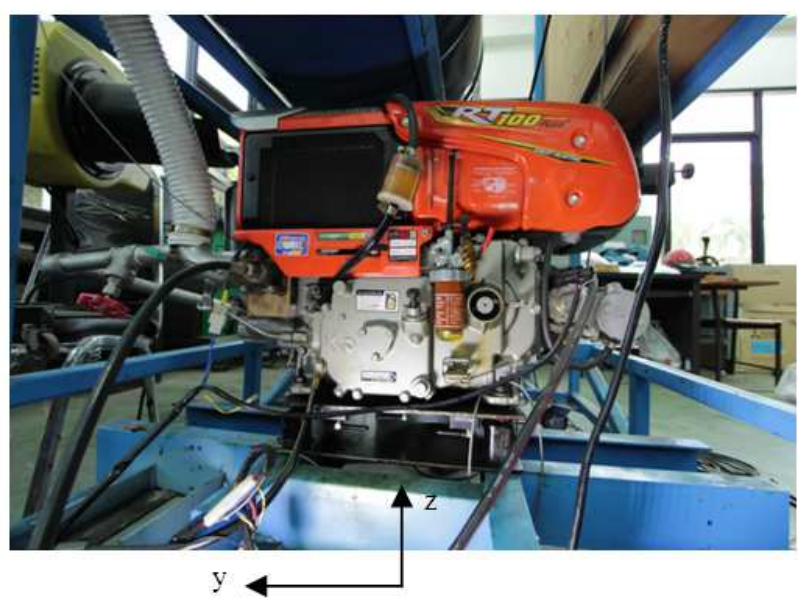

Fig. 1. Kubota "RT100 plus" setup with the engine test bed

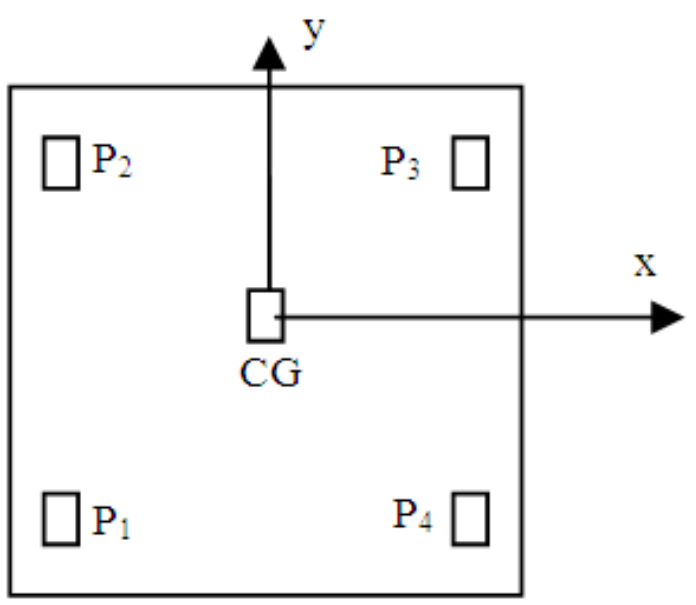

Fig. 2. The accelerometer mounting allocations (top view)

Table 2. Instrumentation specifications

\begin{tabular}{ll}
\hline Instrumentation & Characteristics \\
\hline Glink & Sample rate 2048 samples per channel \\
& per second Measuring acceleration \\
& $\mathrm{X}, \mathrm{Y}$ and Z axes \\
& Rage: $\pm 2 \mathrm{G}$ or $\pm 10 \mathrm{G}$ \\
& On-board flash memory: $2 \mathrm{MB}$ \\
& Power: usb Frequency: \\
WADA base & 2.405 GHz to $2.480 \mathrm{GHz}$. \\
\hline
\end{tabular}

\subsection{Accelerometer}

Five "G-Link" wireless accelerometers are use to measure the engine vibrations at the engine support. Figure 2 and 3 show accelerometer mounting points.

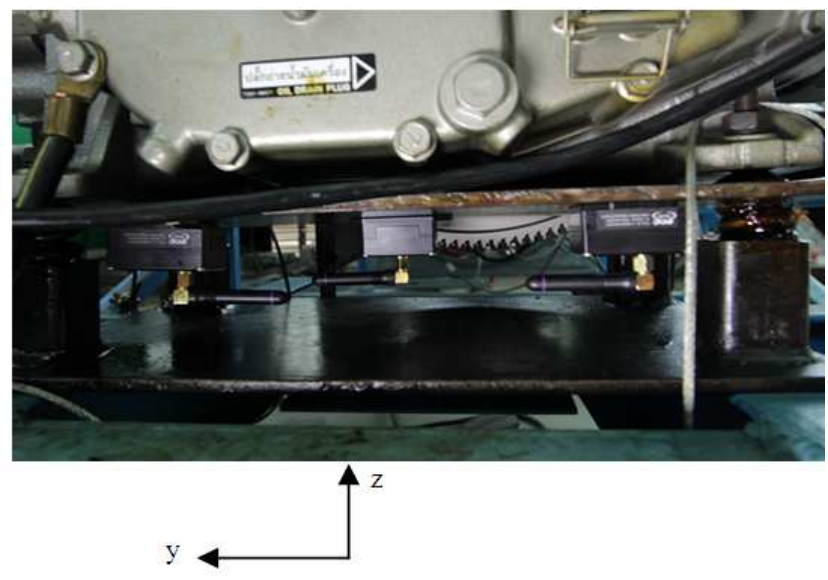

Fig. 3. The accelerometer mounting allocations (front view)

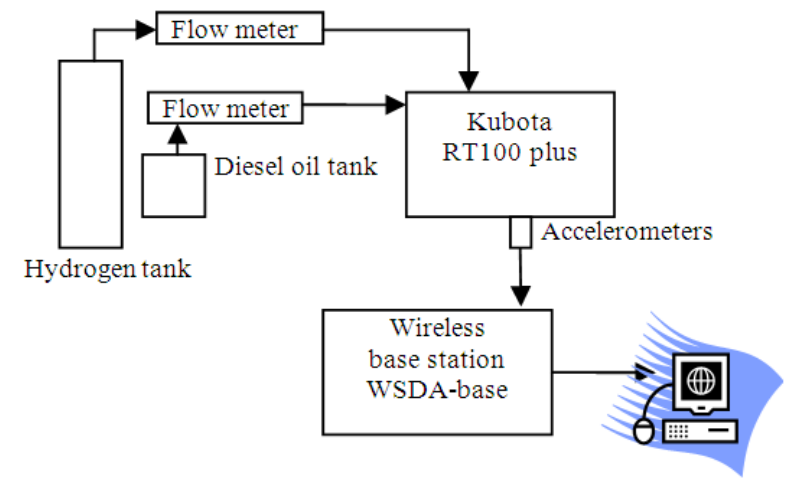

Fig. 4. Schematic of the experimental setup

Table 3. The experimental details

\begin{tabular}{lll}
\hline Experiment & $\mathrm{N}$ & $\mathrm{T}$ \\
\hline Exp. 1 & 2,000 & $25 \%$ \\
Exp. 2 & 2,000 & $50 \%$ \\
Exp. 3 & 1,600 & $15 \%$ \\
Exp. 4 & 1,600 & $25 \%$ \\
\hline
\end{tabular}

The accelerometers are controlled by "Node Commander" software through base station "WADA base". The main technical specifications are show in Table 2.

\subsection{Measuring System Layout}

The schematic diagram of the experimental is shown in Fig. 4.

The hydrogen flows across the flow meter with the pressure of 1 bar before flow into the cylinder. Hydrogen flow rates are controlled by a valve with the values of 0 , 5, 10, 15 and 20L pm. 
Hydrogen percentage $(\% \mathrm{H} 2)$ is percentage of mass fraction between hydrogen consumption and diesel oil consumption Equation 1:

$$
\% \mathrm{H}_{2}=\frac{\mathrm{m}_{\mathrm{H}_{2}}}{\mathrm{~m}_{\mathrm{f}}} \times 100
$$

$\mathrm{m}_{\mathrm{H}_{2}}=$ hydrogen mass flow rate $(\mathrm{kg} / \mathrm{s})$

$\mathrm{m}_{\mathrm{f}}=$ diesel oil mass flow rate $(\mathrm{kg} / \mathrm{s})$
The engine speed and the engine torque details are shown in Table 3.

From the experiment design, we have total 20 study cases for each accelerometer.

\section{RESULTS}

Examples of the engine acceleration graphs at the Center of Gravity (CG) with engine speed (N) 1,600 rpm, Torque (T) $25 \%$ and $\% \mathrm{H}_{2}=0.50 \%$ are shown in Fig. 5-7.

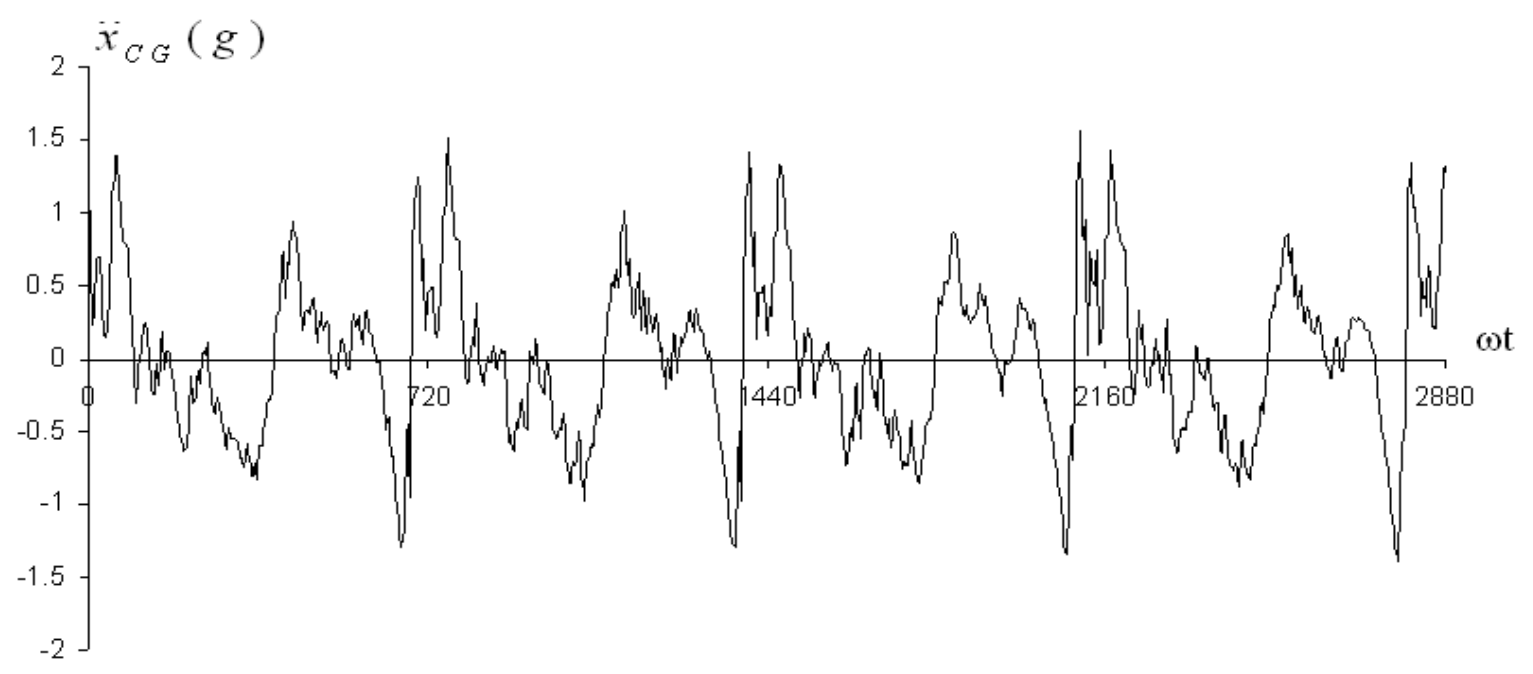

Fig. 5. The engine acceleration at $C G$ in $x$ direction ( $\left.\ddot{X}_{\mathrm{CG}}\right)$

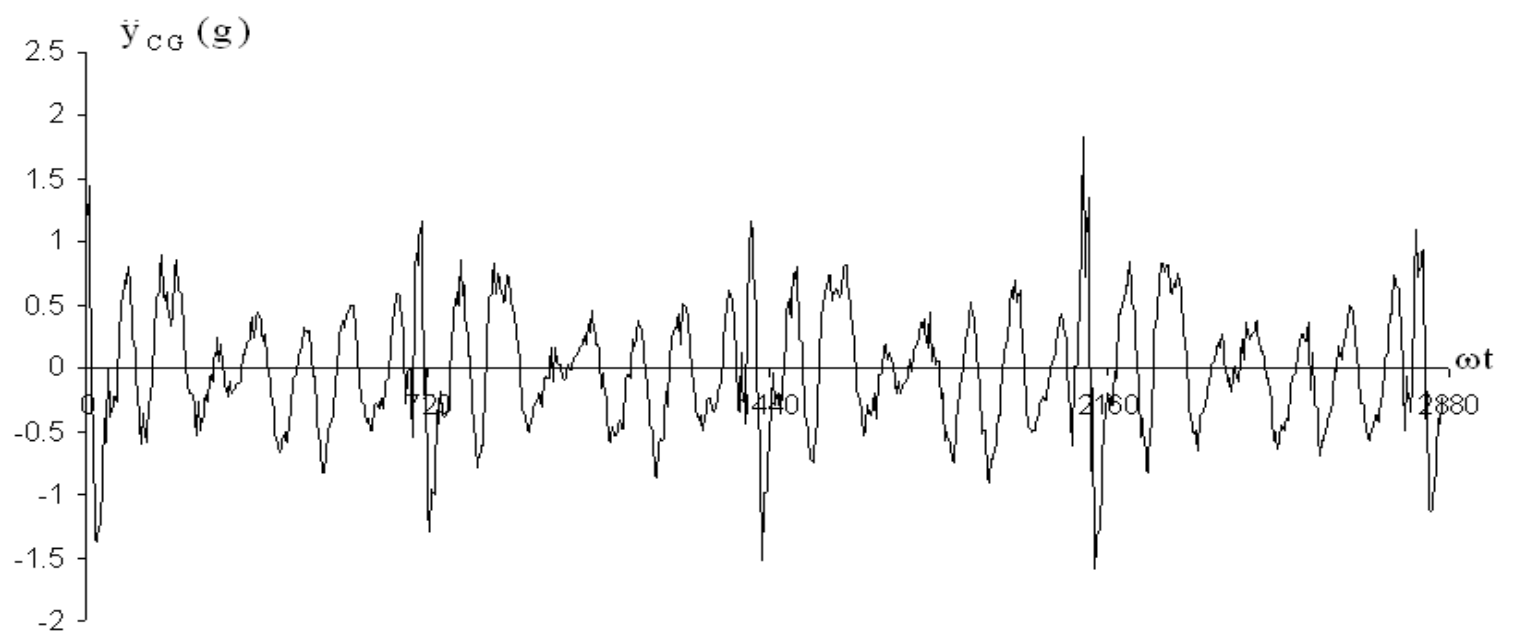

Fig. 6. The engine acceleration at $C G$ in y direction $\left(\ddot{\mathrm{Y}}_{\mathrm{CG}}\right)$ 
Boonthum Wongchai et al. / American Journal of Applied Sciences, 10 (1): 8-14, 2013

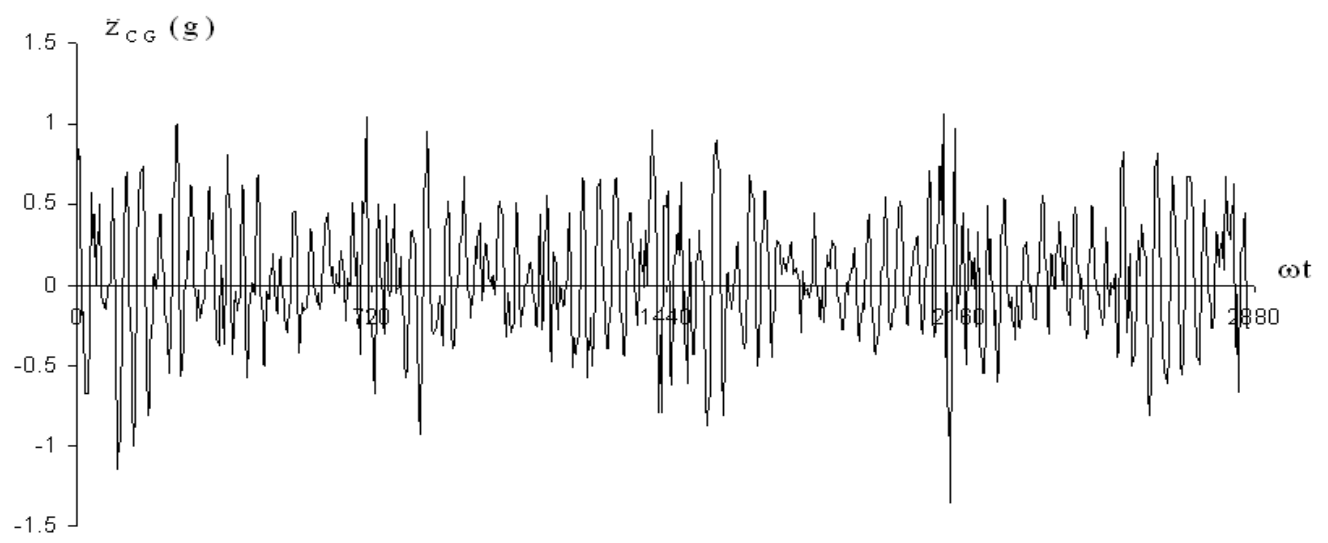

Fig. 7. The engine acceleration at $\mathrm{CG}$ in $\mathrm{z}$ direction $\left(\ddot{\mathrm{z}}_{\mathrm{CG}}\right)$

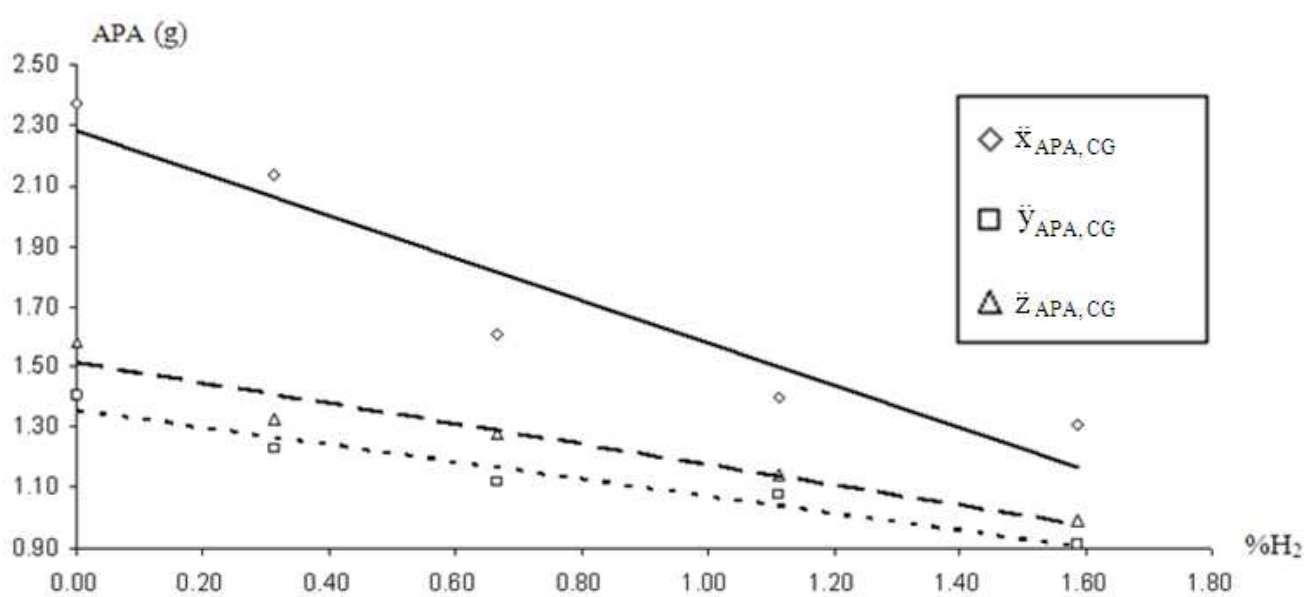

Fig. 8. The average peak acceleration at $\mathrm{CG}($ Exp. $1, \mathrm{~N}=2,000 \mathrm{rpm}, \mathrm{T}=25 \%, \mathrm{n}=1)$

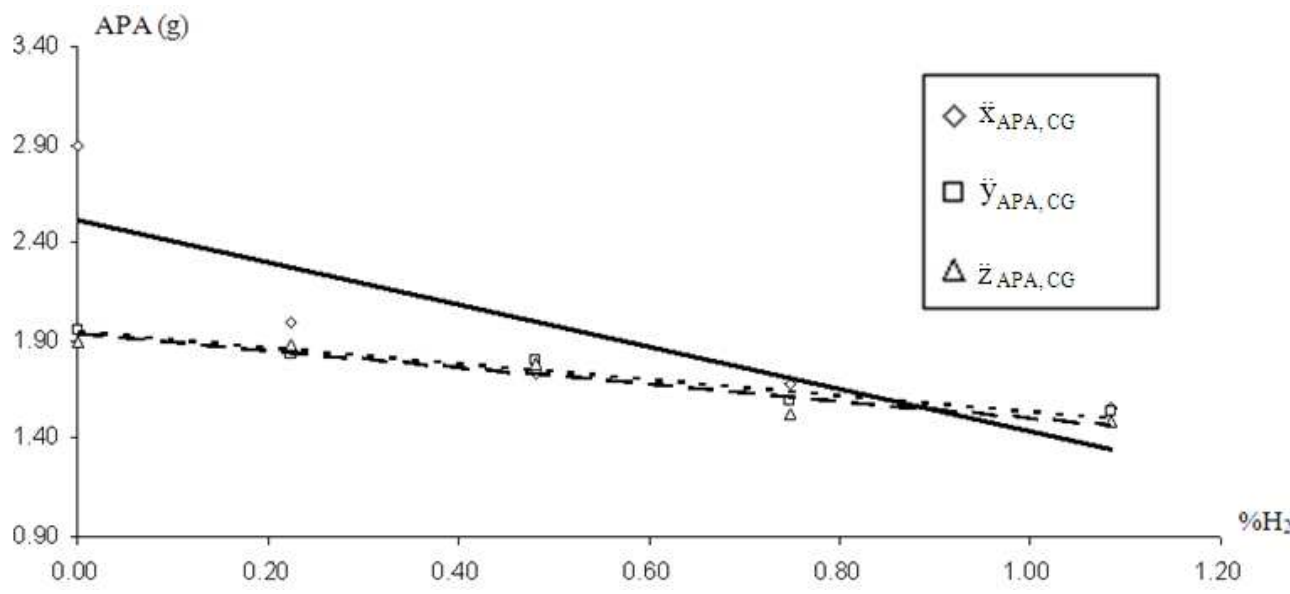

Fig. 9. The average peak acceleration at $C G($ Exp. $2, N=2,000 \mathrm{rpm}, T=50 \%$ and $n=1)$ 
Boonthum Wongchai et al. / American Journal of Applied Sciences, 10 (1): 8-14, 2013

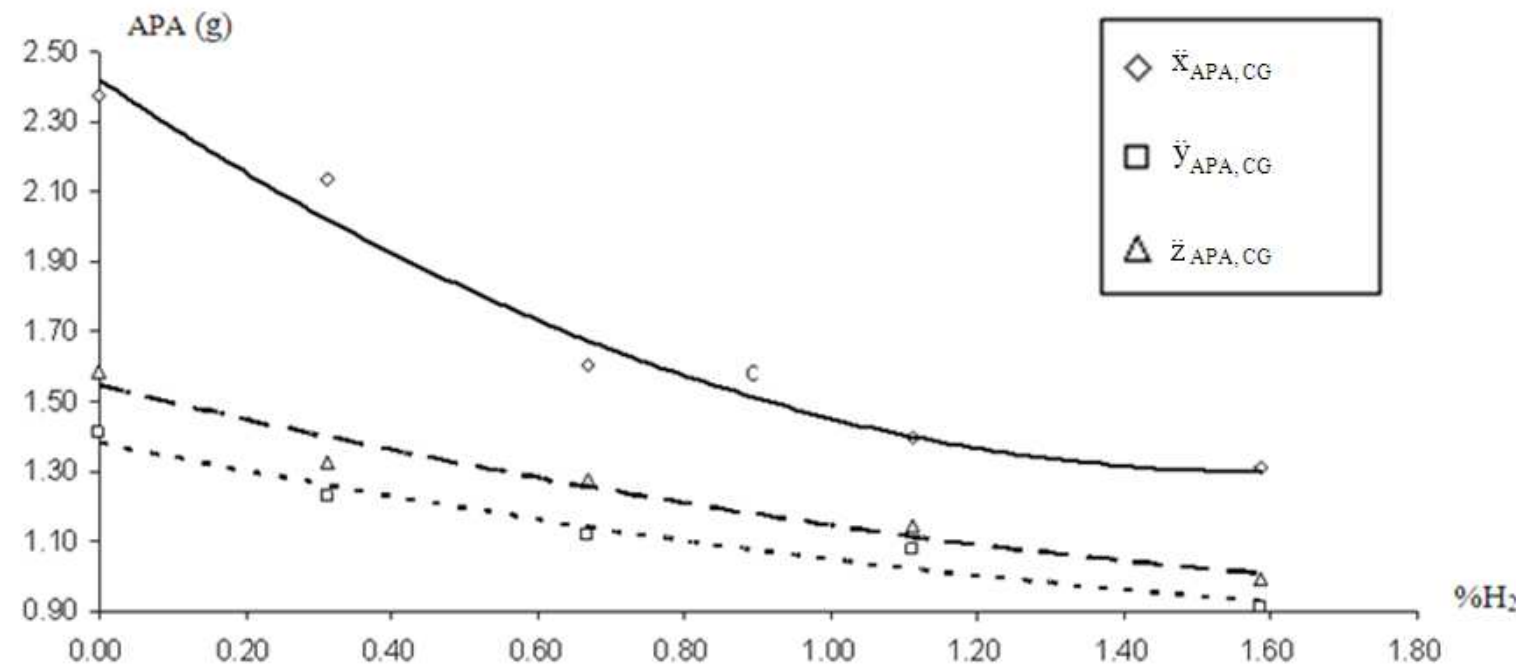

Fig. 10. The average peak acceleration at $C G($ Exp. $1, N=2,000 \mathrm{rpm}, \mathrm{T}=25 \%, \mathrm{n}=2)$

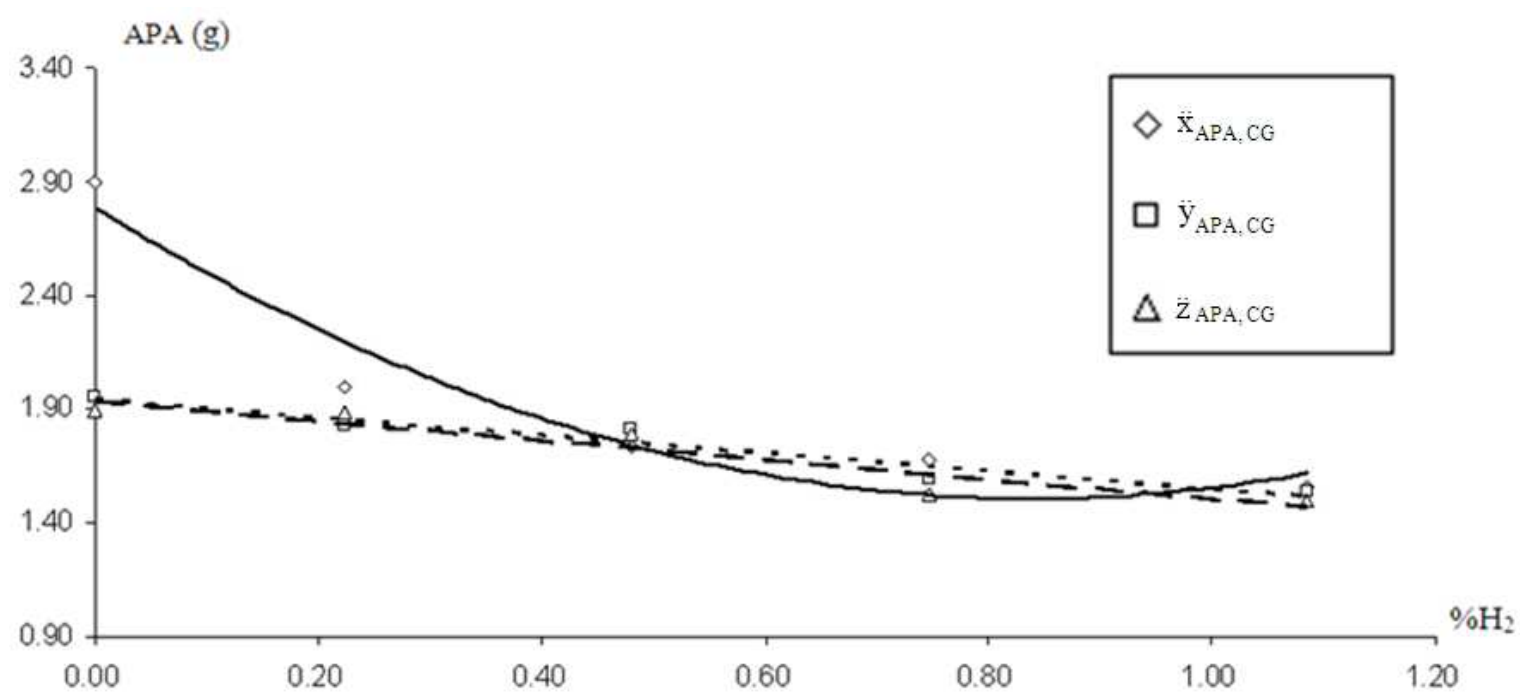

Fig. 11. The average peak acceleration at $C G($ Exp. $2, N=2,000 \mathrm{rpm}, T=50 \%$ and $n=2)$

Table 4. The average peak acceleration APA at CG (Exp. 1, N $=2,000 \mathrm{rpm}$ and $\mathrm{T}=25 \%$ )

\begin{tabular}{|c|c|c|c|c|c|}
\hline & \multicolumn{5}{|l|}{$\% \mathrm{H}_{2}$} \\
\hline & 0 & 0.31 & 0.67 & 1.11 & 1.59 \\
\hline$\ddot{\mathrm{x}}_{\mathrm{APA}, \mathrm{CG}}$ & 2.37 & 2.13 & 1.60 & 1.40 & 1.31 \\
\hline$\ddot{\mathrm{y}}_{\mathrm{APA}, \mathrm{CG}}$ & 1.41 & 1.23 & 1.12 & 1.08 & 1.91 \\
\hline$\ddot{\mathrm{Z}}_{\mathrm{APA}, \mathrm{CG}}$ & 1.58 & 1.33 & 1.28 & 1.14 & 1.99 \\
\hline
\end{tabular}

Table 5. The average peak acceleration APA at CG (Exp. 2, N $=2,000 \mathrm{rpm}$ and $\mathrm{T}=50 \%$ )

\begin{tabular}{llllll} 
& 0 & 0.31 & 0.67 & 1.11 & 1.59 \\
\hline$\ddot{\mathrm{x}}_{\mathrm{APA}, \mathrm{CG}}$ & 2.90 & 2.00 & 1.73 & 1.68 & 1.55 \\
$\ddot{\mathrm{y}}_{\mathrm{APA}, \mathrm{CG}}$ & 1.83 & 1.83 & 1.81 & 1.59 & 1.53 \\
$\ddot{\mathrm{z}}_{\mathrm{APA}, \mathrm{CG}}$ & 1.88 & 1.88 & 1.79 & 1.52 & 1.49 \\
\hline
\end{tabular}


Table 6. APA equations at CG

\begin{tabular}{clllll}
\hline Order & Condition & $\mathrm{a}$ & $\mathrm{b}$ & $\mathrm{c}$ & $\mathrm{R}^{2}$ \\
\hline \multirow{4}{*}{1} & Exp.1 & & & & \\
& $\ddot{\mathrm{x}}_{\mathrm{APA}, \mathrm{CG}}$ & -0.7019 & 2.2799 & & 0.8988 \\
& $\ddot{\mathrm{y}}_{\mathrm{APA}, \mathrm{CG}}$ & -0.2835 & 1.3563 & & 0.9410 \\
& $\ddot{\mathrm{z}}_{\mathrm{APA}, \mathrm{CG}}$ & -0.3385 & 1.5146 & & 0.9395 \\
& Exp.2 & & & & \\
& $\ddot{\mathrm{x}}_{\mathrm{APA}, \mathrm{CG}}$ & -1.0728 & 2.5158 & & 0.7160 \\
& $\ddot{\mathrm{y}}_{\mathrm{APA}, \mathrm{CG}}$ & -0.3984 & 1.9453 & & 0.9397 \\
$\ddot{\mathrm{z}}_{\mathrm{APA}, \mathrm{CG}}$ & -0.4312 & 1.9354 & & 0.8970 \\
& Exp.1 & & & & \\
$\ddot{\mathrm{x}}_{\mathrm{APA}, \mathrm{CG}}$ & 0.4489 & -1.4178 & 2.4206 & 0.9772 \\
& $\ddot{\mathrm{y}}_{\mathrm{APA}, \mathrm{CG}}$ & 0.0829 & -0.4158 & 1.3823 & 0.9582 \\
& $\ddot{\mathrm{z}}_{\mathrm{APA}, \mathrm{CG}}$ & 0.1032 & -0.5031 & 1.5466 & 0.9581 \\
& Exp.2 & & & & \\
$\ddot{\mathrm{x}}_{\mathrm{APA}, \mathrm{CG}}$ & 1.8152 & -3.0472 & 2.7852 & 0.9325 \\
$\ddot{\mathrm{y}}_{\mathrm{APA}, \mathrm{CG}}$ & 0.0509 & -0.4537 & 1.9529 & 0.9414 \\
$\ddot{\mathrm{z}}_{\mathrm{APA}, \mathrm{CG}}$ & -0.0407 & -0.3869 & 1.9294 & 0.8978 \\
\hline & & & &
\end{tabular}

The results show that the engine accelerations are the periodic function for all experiments and all directions with the period of $720^{\circ}$ per revolution. Examples of the Average Peak (APA) of 100 revolutions of the engine are show in Table 4 and 5.

The relation between APA and $\% \mathrm{H}_{2}$ can find by using the regression analysis with $\mathrm{n}^{\text {th }}$ polynomial Equation 2 and 3:

$(n-1) A P A=a\left(\% H_{2}\right)+b$

$(\mathrm{n}-2) \mathrm{APA}=\mathrm{a}\left(\% \mathrm{H}_{2}\right)+\mathrm{bAPA}$

$=\mathrm{a}\left(\% \mathrm{H}_{2}\right)^{2}+\mathrm{b}\left(\% \mathrm{H}_{2}\right)+\mathrm{c}$

Example of APA graph at CG with linear equation $(\mathrm{n}=1)$ are shown in Fig. 8-9 and APA graph with 2nd polynomial equation $(\mathrm{n}=2)$ are shown in Fig. 10-11.

Table 6 shows APA equations and $\mathrm{R}^{2}$ of the APA graphs at $\mathrm{CG}$.

\section{DISCUSSION}

The results for all cases (show some cases in this study) found that the relation between APA and $\% \mathrm{H}_{2}$ can predict by using linear equation with average $\mathrm{R}^{2}=$ 0.8973 or 2 nd polynomial equation with $R^{2}=0.9592$. All graphs are the decreasing function. APA can decrease by increasing $\% \mathrm{H}_{2}$.

\section{CONCLUSION}

The relation between the average peak acceleration and hydrogen percentage can predict by using linear equation or 2 nd polynomial equation. The average peak acceleration can decrease by increasing hydrogen percentage. In the other word, the engine vibrations can decrease by increasing hydrogen percentage.

\section{ACKNOWLEDGMENT}

The present study was conducted at Kasetsart University Si Racha Campus. The authors would like to thank the Kasetsart University Research and Development Institute (KURDI) for the provision of the research grant to this project under the contract number V-T(D)173.53. The Kasetsart University Center for Advanced Studies in Industrial Technology under the National Research University (NRU) project is also acknowledged for the support to this study.

\section{REFERENCES}

Banapurmatha, N.R., P.G. Tewaria and R.S. Hosmath, 2008. Experimental investigations of a four-stroke single cylinder direct injection diesel engine operated on dual fuel mode with producer gas as inducted fuel and Honge Oil and its Methyl Ester (HOME) as injected fuels. Renew. Energy, 33: 2007-2018. DOI: 10.1016/j.renene.2007.11.017

Barelli, L., G. Bidini, C. Buratti and R. Mariani, 2009. Diagnosis of internal combustion engine through vibration and acoustic pressure non-intrusive measurements. Applied Thermal Eng., 29: 17071713. DOI: 10.1016/j.applthermaleng.2008.07.025

Carlucci, A.P., F.F. Chiara and D. Laforgia, 2006. Analysis of the relation between injection parameter variation and block vibration of an internal combustion diesel engine. J. Sound Vibrat., 295: 141-164. DOI: 10.1016/j.jsv.2005.12.054

Cheng, Y., J. Tang, S. Ji and M. Huang, 2012. Combustion timing determination based on vibration velocity in HCCI engines. Mechanism Mach. Theory, 58: 20-28. DOI: 10.1016/j.mechmachtheory.2012.08.004 
Escalante, S.M.A. and A.M. Fernandez, 2010. A review on the technical adaptations for internal combustion engines to operate with gas/hydrogen mixtures. Int. J. Hydrogen Energy, 35: 12134-12140. DOI: 10.1016/j.ijhydene.2009.09.070

Huzayyin, A.S., A.H. Bawady, M.A. Rady and A. Dawood, 2004. Experimental evaluation of Diesel engine performance and emission using blends of jojoba oil and diesel fuel. Energy Conversion Manage., 45: 2093-2112. DOI: 10.1016/j.enconman.2003.10.017

Korakianitis, T., A.M. Namasivayam and R.J. Crookes, 2010. Hydrogen dual-fuelling of compression ignition engines with emulsified biodiesel as pilot fuel. Int. J. Hydrogen Energy, 35: 13329-13344. DOI: 10.1016/j.ijhydene.2010.08.007

Miyamoto, T., H. Hasegawa, M. Mikami, N. Kojima, H. Kabashima and Y. Urata, 2011. Effect of hydrogen addition to intake gas on combustion and exhaust emission characteristics of a diesel engine. Int. J. Hydrogen Energy, 13138-13149. DOI: 10.1016/j.ijhydene.2011.06.144

Lata, D.B., A. Misra and S. Medhekar, 2011. Investigations on the combustion parameters of a dual fuel diesel engine with hydrogen and LPG as secondary fuels. Int. J. Hydrogen Energy, 36: 13808-13819. DOI: 10.1016/j.ijhydene.2011.07.142
Saravanana, N., G. Nagarajana, C. Dhanasekaranb and K.M. Kalaiselvanb, 2007. Experimental investigation of hydrogen port fuel injection in DI diesel engine. Int. J. Hydrogen Energy, 32: 40714080. DOI: 10.1016/j.ijhydene.2007.03.036

Selim, M.Y.E., 2001. Pressure-time characteristics in diesel engine fueled with natural gas. Renew. Energy, 22: 473-489. DOI: 10.1016/S09601481(00)00115-4

Shin, B., Y. Cho, D. Han, S. Song and K.M. Chun, 2011. Investigation of the effects of hydrogen on cylinder pressure in a split-injection diesel engine at heavy EGR. Int. J. Hydrogen Energy, 36: 13158-13170. DOI: $10.1016 /$ j.ijhydene.2011.07.050

Taghizadeh-Alisaraei, A., B. Ghobadian, T. TavakoliHashjin and S. S. Mohtasebi, 2012. Vibration analysis of a diesel engine using biodiesel and petrodiesel fuel blends. Fuel, 102: 414-422. DOI: 10.1016/j.fuel.2012.06.109

$\mathrm{Wu}, \mathrm{H} . \mathrm{W}$. and Z.Y. Wu, 2012. Investigation on combustion characteristics and emissions of diesel/hydrogen mixtures by using energy-share method in a diesel engine. Applied Thermal Eng., 42: 152-162. DOI: 10.1016/j.applthermaleng.2012.03.004 